\title{
Progress toward the construction of a tri-stable genetic toggle switch in E. coli
}

\author{
Jason Lohmueller*, Brendan Hickey, Azeem Kaka, Annie Gao, Jamie Lemon, \\ Victoria Lattanzi, Peter Goldstein, Lick-Kong Tam, Meghan Schmidt, \\ John Cumbers, James Gagnon, Hayato Urabe, Ana Jaklenec and Gary Wessel
}

Address: Brown University, Providence, RI, USA

Email: Jason Lohmueller* - Jason_Lohmueller@Brown.edu

* Corresponding author

from BioSysBio 2007: Systems Biology, Bioinformatics and Synthetic Biology Manchester, UK. II-13 January 2007

Published: 8 May 2007

BMC Systems Biology 2007, I(SuppI I):P39 doi:10.1 I86/I752-0509-I-SI-P39

This abstract is available from: http://www.biomedcentral.com/ I752-0509/I?issue=S I

(c) 2007 Lohmueller et al; licensee BioMed Central Ltd.

In 2000 Gardner and Collins reported the construction of a fundamental genetic regulatory device, the bistable toggle switch in E. coli. We report here a natural extension of this classic device, a tristable genetic toggle switch capable of switching among three stable states. Like the bistable switch, the tristable switch consists of repressible promoters that produce inhibitory proteins and requires only a transient pulse of chemical inducer to switch among stable states. Our initial construct controls the expression of three different fluorescent reporters using the $\mathrm{pBad} / \mathrm{AraC}$, $\mathrm{pLacI} / \mathrm{LacI}$, and pTetR/TetR systems; though it can theoretically be created from any three repressible promoters and can control the expression of any three genes. Due to the anticipated addition of noise resulting from the presence of the additional promoter/repressor, we have modeled the system extensively, creating both a continuous model based on Elowitz 2000 and a stochastic deterministic model based on Isaacs 2003. In addition to modeling our system, we have also explored the possibility of creating switches capable of even more stable states. The tristable toggle switch, constructed and characterized as an iGEM 2006 project at Brown University, is composed entirely of Biobricks from the Registry of Standard Biological Parts. In addition to providing support for the iGEM hypothesis, the tristable toggle switch has implications for biotechnology and gene therapy.

\section{References}

I. Gardner TS, Cantor CR, Collins J]: Construction of a genetic toggle switch in Escherichia coli. Nature 2000, 403(6767):339-42.

2. Elowitz MB, Leibler S: A synthetic oscillatory network of transcriptional regulators. Nature 2000, 403(6767):335-8.

3. Isaacs FJ, Hasty J, Cantor CR, Collins JJ: Prediction and measurement of an autoregulatory genetic module. Proc Natl Acad Sci USA 2003, 100:77I4-9. Epub 2003 Jun 13. 